\title{
Reconnaissance of coastal areas using simulated EnMAP data in an ERDAS IMAGINE Environment \\ Merlin Becker*a, Simon Schreiner ${ }^{\mathrm{a}}$, Stefan Auer ${ }^{\mathrm{b}}$, Daniele Cerra ${ }^{\mathrm{b}}$, Peter Gege ${ }^{\mathrm{b}}$, Martin Bachmann ${ }^{\mathrm{b}}$, Andreas Roitzsch ${ }^{\mathrm{c}}$, Uwe Mitschke ${ }^{\mathrm{c}}$, Wolfgang Middelmann ${ }^{\mathrm{a}}$, \\ ${ }^{a}$ Fraunhofer Institute of Optronics, System Technologies and Image Exploitation IOSB, Gutleuthausstrasse 1, 76275 Ettlingen, Germany; \\ ${ }^{\mathrm{b}}$ German Aerospace Center DLR, Münchener Strasse 20, 82234 Weßling-Oberpfaffenhofen; \\ ${ }^{c}$ Zentrum für Geoinformationswesen der Bundeswehr ZGeoBw, Kommenerstrasse 188, 53879 Euskirchen
}

\begin{abstract}
Operations in a military naval context require a detailed planning and information gathering. For this purpose, remote sensing is a useful technique without in-situ survey. A collaboration of Fraunhofer IOSB (Institute of Optronics, System Technologies and Image Exploitation), DLR (German Aerospace Center), and Bundeswehr Geoinformation Centre ZGeoBw, engineered a desktop Geoinformation (GIS) plug-in to generate bathymetric charts and land-use-classes (vegetation, soil types and minerals) using hyperspectral data of coastal areas. These data are basis for further analyses like trafficability, barrier detection and change detection. To evaluate the potential of satellites launched in the near future with hyperspectral sensors onboard (EnMAP), aerial hyperspectral data (HySpex, AISA) were collected over a test site near the Wismar Bay in Germany and are used to simulate the satellite hyperspectral data with corresponding recording terms. Additionally, a field campaign was conducted at the Wismar Bay to acquire a ground truth dataset for model validation, including soil spectra and water depths as well. For generating the bathymetric charts, the WASI (Water Color Simulator) approach was adapted, which offers additional information besides water depth (e.g. dissolved matter, brightness of sand, relative amount of sea grass and other properties). Resulting bathymetric charts with a depth up to eight meters and unsupervised classifications of land cover are free of artefacts and accurate. A validation process is in progress. The engineered desktop GIS plug-in for HEXAGON ERDAS IMAGINE software was developed using the native SDK in addition with interoperable scripts like Python. The existing plug-in framework is variable and adaptable to different kind of GIS.
\end{abstract}

Keywords: Bathymetry, hyperspectral, EnMAP, ERDAS IMAGINE

\section{INTRODUCTION}

To secure the success of a military naval (landing) operation and to guarantee the best possible protection of the marines, a detailed knowledge about the operation theatre is required. As the mission's sites are mostly remote from well-known coastal areas or situated in regions with limited access, information gathering without an in-situ survey is necessary. Information content to support the mission planning could be: water depth, underwater obstruction, coastal line, coastal condition, land-use, visibility, trafficability, etc.

Remote sensing technologies are already widely used in military context [2, 8, 18]. Flying platforms and their corresponding sensor-(systems) experienced a fast development during the last decade $[10,13,16]$, mainly driven by the establishment of drone technology, active 3D point measurements and the increasing number of operating sensor channels. Passive sensors with the highest number of imaging bands are the so-called hyperspectral (HS) sensors or spectrometers. Their airborne installation, image acquisition and analysis is already state of the art $[8,11,12,17]$ and the data offers ground resolution in a centimeter scale. Since hyperspectral sensors are becoming smaller, their usage on drones is just upcoming [1,4]. So far, the only spaceborne hyperspectral missions have been experimental, with limited capabilities in terms of signal to noise ratio, swath width, and acquisition time. The next years will witness the launch of 
the first hyperspectral missions without the aforementioned problems. One of the first will be the German satellite EnMap (Environmental Mapping and Analysis Program), whose launch is planned for May 2020 [9].

To satisfy requirements on a remote sensing system for military purposes such as described above, a collaboration of Fraunhofer IOSB (Institute of Optronics, System Technologies and Image Exploitation), DLR (German Aerospace Center) and the Bundeswehr Geoinformation Centre ZGeoBw was established. The EnMap sensor has been considered for its potential to derive both coastal bathymetric and land-use information with a short revisit time, with better accuracy with respect to RGB or multispectral systems. Due to the lack of real EnMAP data so far, an airborne hyperspectral data acquisition followed by a spaceborne hyperspectral data simulation was organized. Two planes with several spectrometers onboard (HySpex, AISA) collected hyperspectral aerial images over a test site near Wismar Bay in Germany. At the same time, a team on the ground acquired in-situ data, including soil spectra and water depths.

Next task was the development of techniques to determine the bathymetric information of coastal areas and land-useclasses (vegetation, soil types and minerals). As an optional step, a fusion with co-registered satellite data of higher spatial resolution is possible. By the calculation of coefficients using reflection values of distinct wavelengths, the unsupervised identification of several land-cover-classes is possible. A differentiation of water and terrestrial pixel leads to a clear water mask. Concentrating on terrestrial pixels, those with photosynthetically active, non-photosynthetically active vegetation and soil-covered pixel are distinguished. Focusing on soil pixels, the analysis of special absorption features in the spectra allows quantifying the relative concentration of specific minerals (clay, carbonate and iron oxide). On pixel classified as water, the WASI (Water Color Simulator) after Gege [7] was adapted and applied to generate bathymetric information. WASI models effects on the watercolor (including depth, type of seabed, water turbidity, sun angle, etc.) by matching measured with simulated hyperspectral information. When the simulated and the real reflection spectra are congruent, effects on watercolor including the water depth, the class of ground cover, etc. can be extracted.

The algorithms for processing hyperspectral data were implemented, tested and finally integrated into a user friendly Graphical User Interface (GUI) of an ERDAS IMAGINE environment. The engineered desktop GIS plug-in eases the usability of the developed technology for the end-user. As the modules of the interface were developed consistently and independently from each other, a future modular expandability, optimization and parallelization is possible.

\section{SYSTEM DESIGN}

An overview of the main steps in system development, shortly introduced in chapter 1, is shown in Figure 1 (left). Figure 1 (right) explains the methodical procedure of the chosen methods. The two ways of hyperspectral data acquisition, the chosen analyzing methods and the process of GUI coding will be described in the following chapters.
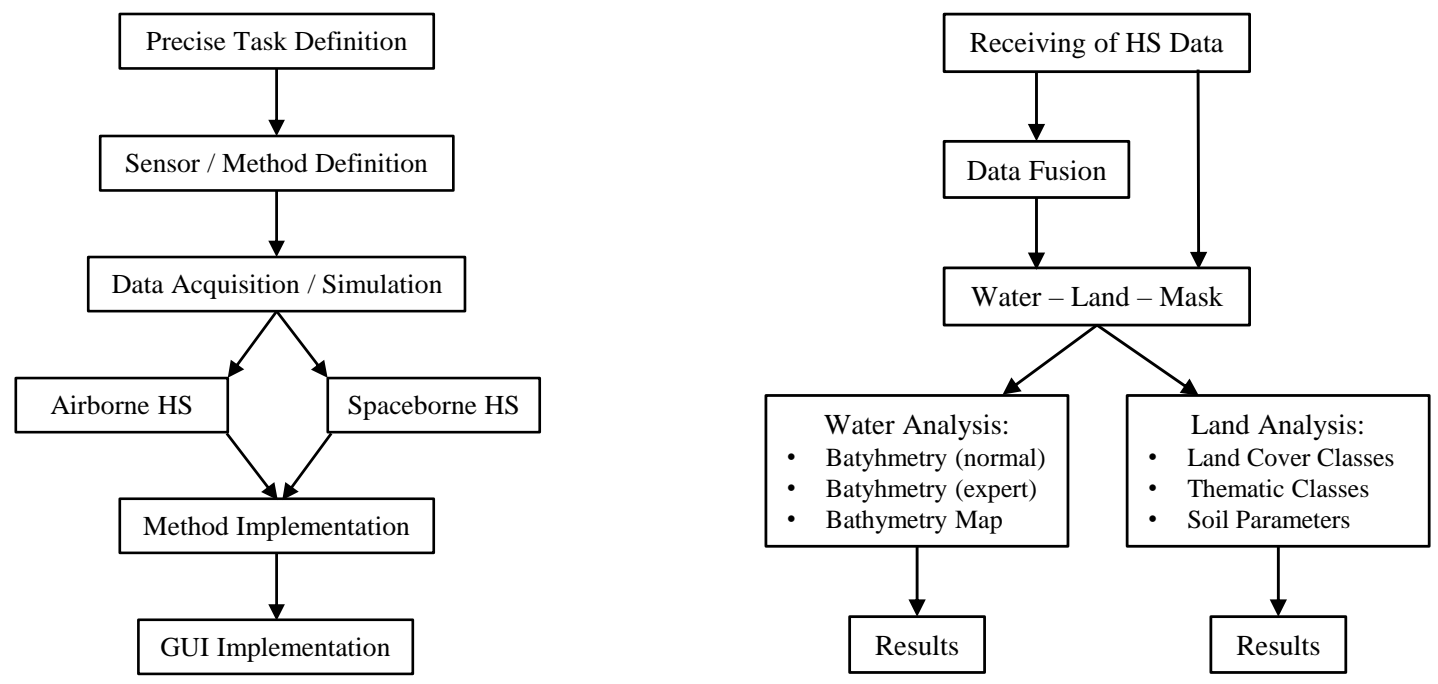

Figure 1: Left: Flowchart of system design process. Right: Flowchart of methodical procedure of the system design 


\section{Airborne Hyperspectral Data Acquisition}

The installation of sensor systems in a plane is much easier than on a satellite. While the changing of the orbit of a satellite is quite complicate, a plane is much more flexible. Unfortunately, this flexibility means a quite unstable orientation during the flight, campaign planning and conducting effort. The influence of the atmosphere, clouds and their shadows, sun glint etc. effect both airborne and spaceborne images. These errors in measurement have to be corrected in post-processing. Due to the lower flight height of planes, the ground resolution of the collected data is much higher than the ones of satellites, which means i.e. a higher detectability of small objects, with the drawback of a smaller swath width and therefore size of the imaged area on ground.

Because operability is a major criterion in military context, Fraunhofer IOSB developed a ready to fly sensor wingpod [17]. The set of sensors installed includes a hyperspectral camera (aisaEagle: 390-990nm, 128 bands, aisaHawk: 992500nm, 239 bands), a LiDAR system (Riegl VQ-580) and an IMU/INS sensor (Applanix) to record permanently the exact position and orientation during the flight (Figure 2). Due to its wingspan, the motorized glider "Stemme S10" as airborne platform offers a stable and far-reaching flight (up to $1000 \mathrm{~km}$ ). The "Stemme S10" is easy to service and can carry an additional wingpod for the real-time downlink to a ground station [10]. On a flight height between $600-750 \mathrm{~m}$ a geometric resolution of $50 \mathrm{~cm}$ for the HS-camera and $1-4 \mathrm{pts} / \mathrm{m}^{2}$ for the LiDAR sensor are achieved.

DLR acquired the aerial hyperspectral data with a "HySpex" sensor system installed on a Cessna airplane. Two camera bodies of the Norsk Elektro Optikk (NEO) company collect spectral data between 416-1000nm in the VNIR range using 160 bands and 1000-2498 $\mathrm{nm}$ in the SWIR wavelength range using 256 bands.
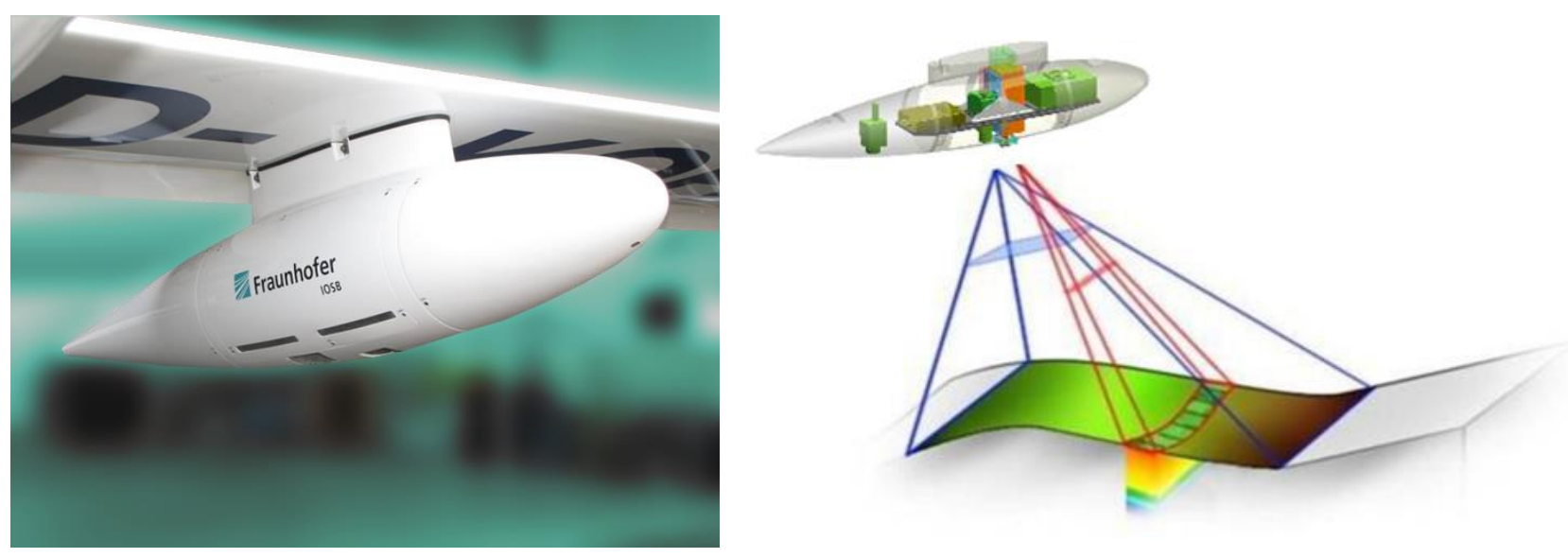

Figure 2: Hyperspectral sensor system (wingpod) and principle of data acquisition

\section{Spaceborne Hyperspectral Data Acquisition}

Recently, most hyperspectral imagery applications are performed using airborne acquired images due to the low availability and quality of spaceborne data. The Environmental Mapping and Analysis Program (EnMAP) is a German earth observation satellite with the mission to provide global coverage of spaceborne hyperspectral imagery. Its launch is planned for 2020 [9]. EnMAP will be equipped with a dual-spectrometer instrument, which measures reflectance in the range between 420 and $2450 \mathrm{~nm}$ resulting in 242 available bands with a spatial resolution of $30 \mathrm{~m}$ [9]. As EnMAP data are not yet available, data sets are simulated for this project [6]. The simulation is performed based on airborne HySpex data. The result is a hyperspectral image comparable with future EnMAP recording terms with a spatial resolution of 30 $\mathrm{m}$ and 242 bands, but without exact spectral resampling.

The advantage of spaceborne acquired hyperspectral imagery is the global coverage and relatively short revisit time of the acquisitions. EnMAP for instance will have a temporal resolution up to four days, which allows up to date acquisitions across the globe [9]. However, even though high-resolution spaceborne remote sensing imagery will be available, the ground sampling distance of airborne acquired data is higher, which is of great importance for some applications [2]. 


\section{Methods}

For the realization of the ERDAS IMAGINE plug-in, the methodical procedure was implemented within three modules, named Data Fusion, Land Analysis and Water Analysis. They are described in Table 1 and shown as overview in Figure 1 (right).

Table 1: Description of the implemented methods.

\begin{tabular}{|c|c|c|c|c|}
\hline Module & Tool & Input Data & Applied Method & Target / Output Data \\
\hline $\begin{array}{l}\text { Data } \\
\text { Fusion }\end{array}$ & Data Fusion & $\begin{array}{l}\text { Hyperspectral Low } \\
\text { Spatial Resolution } \\
\quad \text { Image } \\
\quad+ \\
\text { Multispectral High } \\
\text { Spatial Resolution } \\
\text { Image }\end{array}$ & $\begin{array}{c}\text { Coupled Non-Negative Matrix } \\
\text { Factorization (CNMF) algorithm for Data } \\
\text { Fusion [21] }\end{array}$ & $\begin{array}{l}\text { Image with both high } \\
\text { spectral and spatial } \\
\text { resolution }\end{array}$ \\
\hline \multirow{4}{*}{$\begin{array}{c}\text { Land } \\
\text { Analysis }\end{array}$} & $\begin{array}{l}\text { Water Land } \\
\text { Mask }\end{array}$ & Hyperspectral Image & $\begin{array}{c}\text { Calculation of three Coefficients for } \\
\text { differentiating Land, Shallow Water and } \\
\text { Deep Water [19] }\end{array}$ & $\begin{array}{l}\text { 3-Band Image with } \\
\text { three Coefficients } \\
\text { or } \\
\text { 1-Band Image with a } \\
\text { Water Land Mask }\end{array}$ \\
\hline & $\begin{array}{l}\text { Land Cover } \\
\text { Classes }\end{array}$ & $\begin{array}{c}\text { Hyperspectral Image } \\
+ \\
\text { Water Land Mask } \\
(1-\text { Band })^{*}\end{array}$ & $\begin{array}{c}\text { Calculation of three Coefficients for } \\
\text { differentiating Photosynthetic Active } \\
\text { Vegetation [20], Photosynthetic Inactive } \\
\text { Vegetation [5] and Soil / Impervious } \\
\text { Surfaces [3] }\end{array}$ & $\begin{array}{c}\text { 3-Band Image } \\
\text { depicting the } \\
\text { Proportions of the } 3 \\
\text { Classes }\end{array}$ \\
\hline & $\begin{array}{l}\text { Thematic } \\
\text { Classes }\end{array}$ & $\begin{array}{c}\text { Hyperspectral Image } \\
+ \\
\text { Water Land Mask } \\
(1 \text {-Band })^{*} \\
+ \\
\text { Land Cover Classes* }\end{array}$ & $\begin{array}{c}\text { Classification of Hyperspectral Image } \\
\text { based on Results of previous Land Module } \\
\text { Tools. Derivation of } 5 \text { Classes: No Data, } \\
\text { Water, Soil / Impervious Surfaces, } \\
\text { Photosynthetic Active Vegetation and } \\
\text { Photosynthetic Inactive Vegetation }\end{array}$ & $\begin{array}{l}\text { Classified Image / } \\
\text { Thematic Map } \\
\text { depicting the } \\
\text { Distribution of the } 5 \\
\text { Classes }\end{array}$ \\
\hline & Soil Parameters & $\begin{array}{c}\text { Hyperspectral Image } \\
+ \\
\text { Water Land Mask } \\
(1-B a n d) * \\
+ \\
\text { Land Cover Classes* }\end{array}$ & $\begin{array}{c}\text { Determination of relative content of three } \\
\text { mineral groups Clay, Carbonate or Iron } \\
\text { Oxide based on their spectral } \\
\text { characteristics, in areas where pixels are } \\
\text { classified as Soil / Impervious Surfaces } \\
\text { [15]. }\end{array}$ & $\begin{array}{l}\text { One-Band Image } \\
\text { containing the relative } \\
\text { content of the } \\
\text { corresponding mineral } \\
\text { group }\end{array}$ \\
\hline \multirow{3}{*}{$\begin{array}{l}\text { Water } \\
\text { Analysis }\end{array}$} & $\begin{array}{l}\text { Bathymetry } \\
\text { Standard Mode }\end{array}$ & Hyperspectral Image & $\begin{array}{l}\text { Derivation of a Bathymetric Chart by } \\
\text { applying the methods implemented in the } \\
\text { Water Colour Simulator (WASI) [7] The } \\
\text { necessary parameter settings are reduced to } \\
\text { a minimum by applying empirical values. }\end{array}$ & $\begin{array}{l}\text { Six-Band Image } \\
\text { describing six } \\
\text { characteristics (water } \\
\text { depth, amount of Sea } \\
\text { Grass/Dissolved } \\
\text { matter, ...) }\end{array}$ \\
\hline & $\begin{array}{l}\text { Bathymetry } \\
\text { Expert Mode }\end{array}$ & Hyperspectral Image & $\begin{array}{l}\text { Derivation of a Bathymetric Chart by } \\
\text { applying the methods implemented in the } \\
\text { Water Colour Simulator (WASI) [7] All } \\
\text { parameters have to be set by the user, which } \\
\text { requires detailed information about the } \\
\text { study area. }\end{array}$ & $\begin{array}{l}\text { Six-Band Image } \\
\text { describing six } \\
\text { characteristics (water } \\
\text { depth, amount of Sea } \\
\text { Grass/ Dissolved } \\
\text { matter, ...) }\end{array}$ \\
\hline & $\begin{array}{l}\text { Bathymetry } \\
\text { Map }\end{array}$ & $\begin{array}{c}\text { Bathymetry Layer of } \\
\text { Bathymetry Result }\end{array}$ & $\begin{array}{c}\text { Derivation of a colored Bathymetric Map } \\
\text { based on Histogram Values }\end{array}$ & $\begin{array}{l}\text { Colored Image } \\
\text { depicting different } \\
\text { Water Depths }\end{array}$ \\
\hline
\end{tabular}

\footnotetext{
* Input can also be calculated within the tool if not existent.
} 
After receiving the (simulated) EnMAP hyperspectral data, optionally a fusion with co-registered satellite data of higher spatial resolution can be performed. Caused by the systemic properties of sensors with very high spectral resolution, the geometric resolution is low (EnMAP: 30 x 30 m per pixel). In contrast, multispectral sensors (i.e. Sentinel) with just a few bands acquire data with a higher geometric resolution. To increase the geometric resolution while keeping the high spectral resolution, the fusion of HySpex data with co-registered Sentinel data is already implemented using the "Coupled Non-Negative Factorization" algorithm, based on the principle of "Spectral Unmixing" [21]. The fusion of (simulated) EnMAP and Sentinel data requires a high-precision co-registered data-set and an adjustments of the fusion tool This implementation is planned for the future. To separate land surfaces from shallow and deep waters, and to discriminate different land cover classes (photosynthetically active vegetation, photosynthetically inactive vegetation, soil / impervious surfaces), spectral indices using specific bands in the visible and short wave infrared were calculated [3, $5,19,20]$. The classification of relative mineral contents (clay, carbonate and iron oxide) is based on the calculation of continuum removal and the depth of absorption features at specific wavelengths after continuum removal [15].

The WASI (Water Color Simulator) model of Gege [7] was used for generation of the bathymetric charts. The spectral response of water is influenced by its depth and other effects such as sea ground, the concentrations of dissolved matter and surface reflection. The WASI model (inverse model) estimates up to 40 parameters and fits the resulting spectra to the measured aerial/satellite data spectra. When the simulated and the real spectra are congruent, the water depth can be estimated. In this model, ambiguities might occur as different combinations of the 40 parameters may lead to similar reflection spectra. These ambiguities are avoided, if data acquisition is performed under good weather conditions (e.g. few clouds, clear atmosphere, low surface reflection on water, clear water), so the number of fitting parameters can be limited and value ranges are reduced to a realistic interval. Depending on the weather conditions and operation site, some standard values can be determined, which form the basis for the model performance in the so-called "Standard Mode". If several of these parameters are known or measured, they can be set to fixed values in the "Expert Mode". To derive an automated bathymetric map based on the histogram values, the water analysis tool "Bathymetric Map" has to be executed. Another advantage of this inverse model is the additional information profit next to water depth. Dissolved matter, brightness of sand, relative amount of sea grass and other properties are estimated as well.

\section{Graphical User Interface (GUI)}

The modules with their individual tools are integrated into the ERDAS IMAGINE Graphical User Interface (GUI) as a plug-in (see Figure 3 right). The plug-in functions as a middleware between communication of the single modules, and as integration into the ERDAS IMAGINE environment. Three main components assume the most important tasks (Figure 3 left). The ERDAS Controller involves the Hexagon Development KIT (SDK), and is able to access native functions on the software. Therefore, the Controller controls the interaction with the user and provides an interaction between the implemented modules and functions defined in ERDAS. The Datahandler maintains temporal data internally and supervises the data import and resulting data so that the visualization of the data is guaranteed. Lastly, the Scheduler observes and regulates the modules and their sequential calculation parts. Due to the high amount of parameters used for the bathymetric module, a generalized interface using ini-files was chosen. Status files are written permanently to give feedback of the progress. Next to these three components, multiple scripts and libraries such as ERDAS macro language (EML) are available for embedding the GUI and its icons and buttons, and to check the correct format of the user input. All libraries and module scripts (i.e. GDAL) are stored centrally and are executed by a Phyton 2.7 interpreter. 


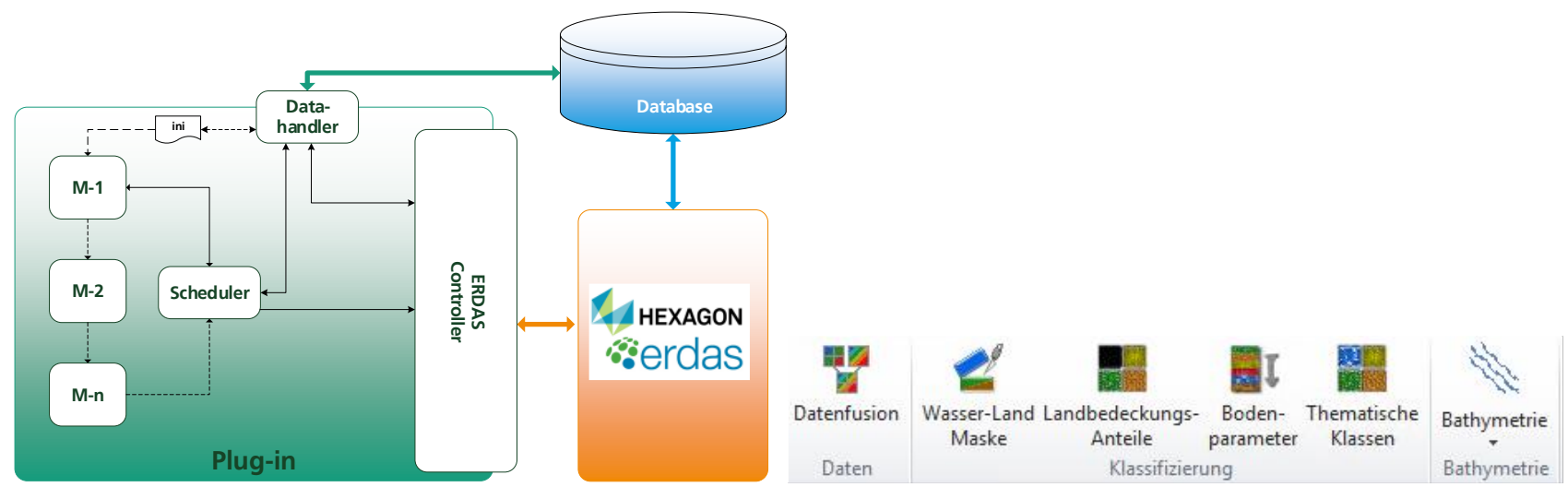

Figure 3: System design of the ERDAS IMAGINE plug-in (left) and the resulting GUI

\section{EXPERIMENT AND REALIZATION}

The test site was a $14 \mathrm{~km} \times 14 \mathrm{~km}$ coastal area at the Wismar Bay, Germany. The maximum water depth of this bay is approx. 15 meters, which makes this site to an interesting area for bathymetry. Flight paths of the area-covering flight campaign were defined to cover water but also land areas of different types. Due to the absence of the algae bloom (low turbidity) and a comparable low water plants density, spring (April) was chosen as timeframe for the campaign. As the sun angle is quite low during this season, the apex of the sun's motion was already at $11 \mathrm{am}$. The flight direction was N$\mathrm{S}$ so the sun glint effect was as weak as possible. To prevent errors during the essential flight campaign, all sensors were tested in laboratory, mounted in the plane and tested in the air before the first day of the flight campaign. With a field of view of about $22.5^{\circ}, 100$ knots plain speed, $20 \%$ overlap of the flight stripes, a flight height of $600 \mathrm{~m}$ and 36 stripes were necessary to cover the described test site. Additionally several points on the ground were scanned from three different directions, so the correction of transformation between the different coordinate systems (camera and IMU) can be performed. This method is called boresight correction.

Reference data were collected for the bathymetric part (water depth, classification and spectral measurement of the sea ground, spectral measurement of the sea surface) and the land-use part (spectral surface measurement and soil samples). Water depths were measured using sonar and Secchi discs, hyperspectral data with an ASD FieldSpec Pro® spectrometer and self-constructed spectrometers by DLR for underwater spectral measurements. The collected reference data were important for processing and correcting the flight data, the model/method training and the final validation process. Especially the spectral data base of the sea ground is important to train the WASI model. The better the knowledge of the sea ground and the model training is, the better the final water depth calculation will be.

Data processing included radiometric correction, geometric correction (georeferencing using reference and IMU/INS data, boresight correction), atmospheric correction based on ATCOR [14] and mosaicking (arranging collected flight stripes). Due to the high data volume, appropriate server structures and processing chains are necessary.

\section{RESULTS}

\section{GUI}

Every user interface window is structured in a consistent scheme. Firstly in- and output directories and files are defined. Depending on the module, different parameters need to be set. Depending on the approximate calculation time, necessary information can be extracted out of already existing results (water-land mask, land cover classes, ...) or temporary calculated again in the background.

Only if all necessary parameters are defined, the calculation can be started. A status window gives feedback on the running process. This structuring scheme corresponds to the usual window pattern of other ERDAS IMAGINE tools. The plug-in runs on ERDAS IMAGINE 2014, 2015 and 2016 and is upward compatible. As EML is a XML based script language, changes on design and layout can be applied without editing the entire plug-in. 


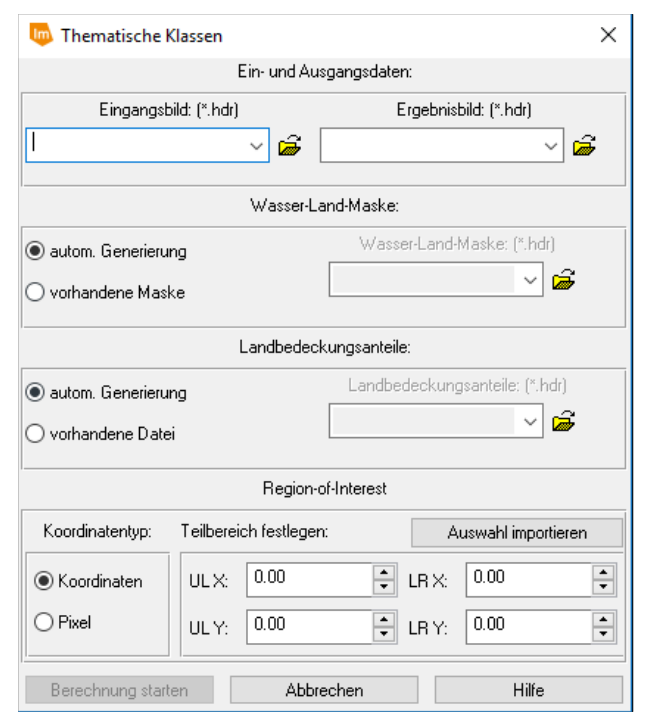

Figure 4: Example of a GUI window

\section{Land-use-classes}

The result of the first land-use-class "water" is presentable in two different kind of ways. Figure 5 (left) shows on the left side a water mask as a greyscale image, where black means no data available, grey connotes water and white represents land surfaces. As there were three coefficients calculated, a more detailed view is possible by visualizing each coefficient as a color of a RGB image (Figure 5 right). If coefficients one, two and three are displayed in red, green and blue respectively, land surfaces appear red, deep water blue and shallow water green or cyan (the deeper the water, the more the color approaches cyan as a mixture of green and blue). By monitoring the water mask results, no schematic errors appeared. In contrast, even small rural water bodies were detected accurately and without confusion with shadow pixels.
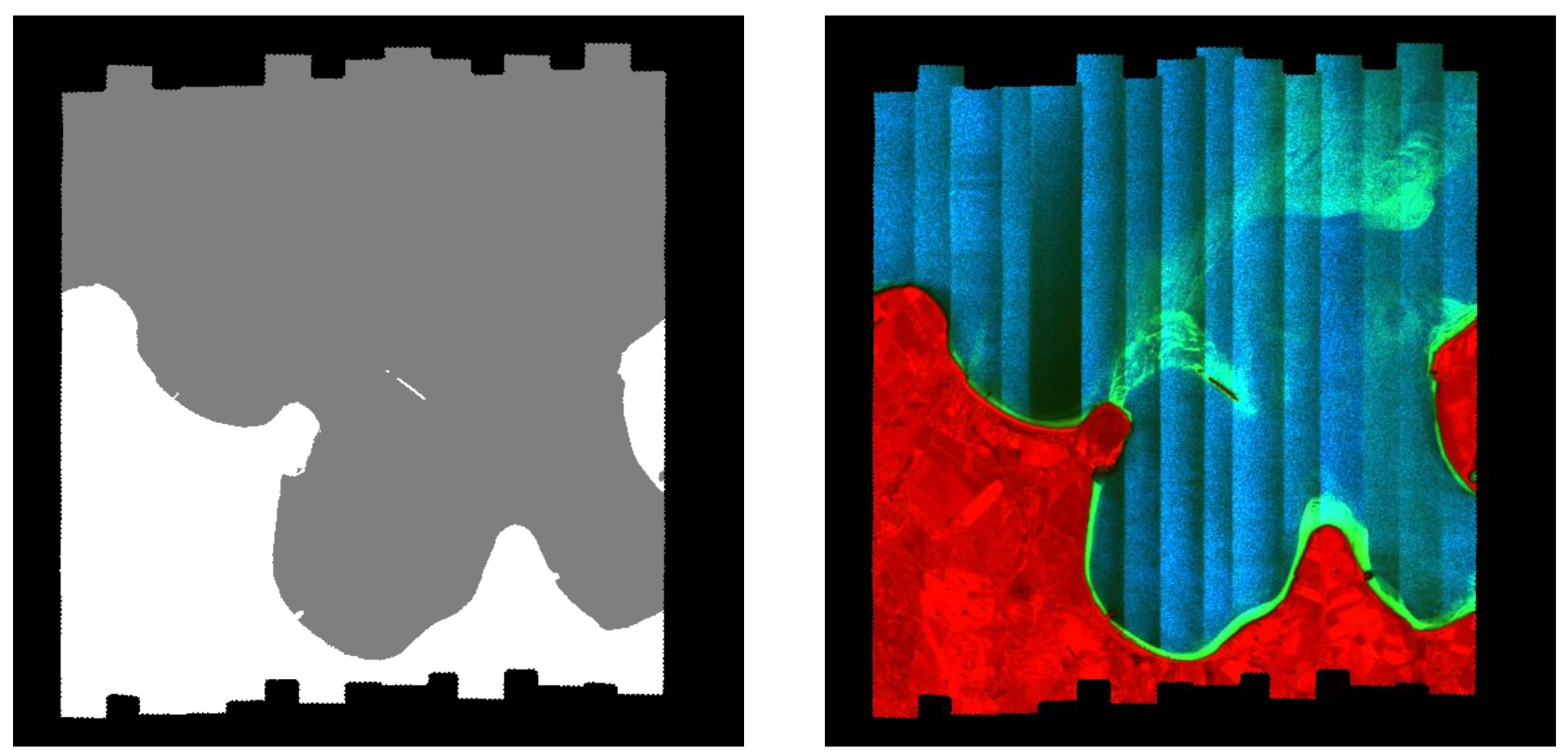

Figure 5: Left: Water mask as greyscale image ( $0=$ no data, black; $1=$ water, grey; $2=$ land, white $)$ Right: Water mask as RGB image (Red = land, red; Green = shallow water, cyan; Blue = deep water, blue) 

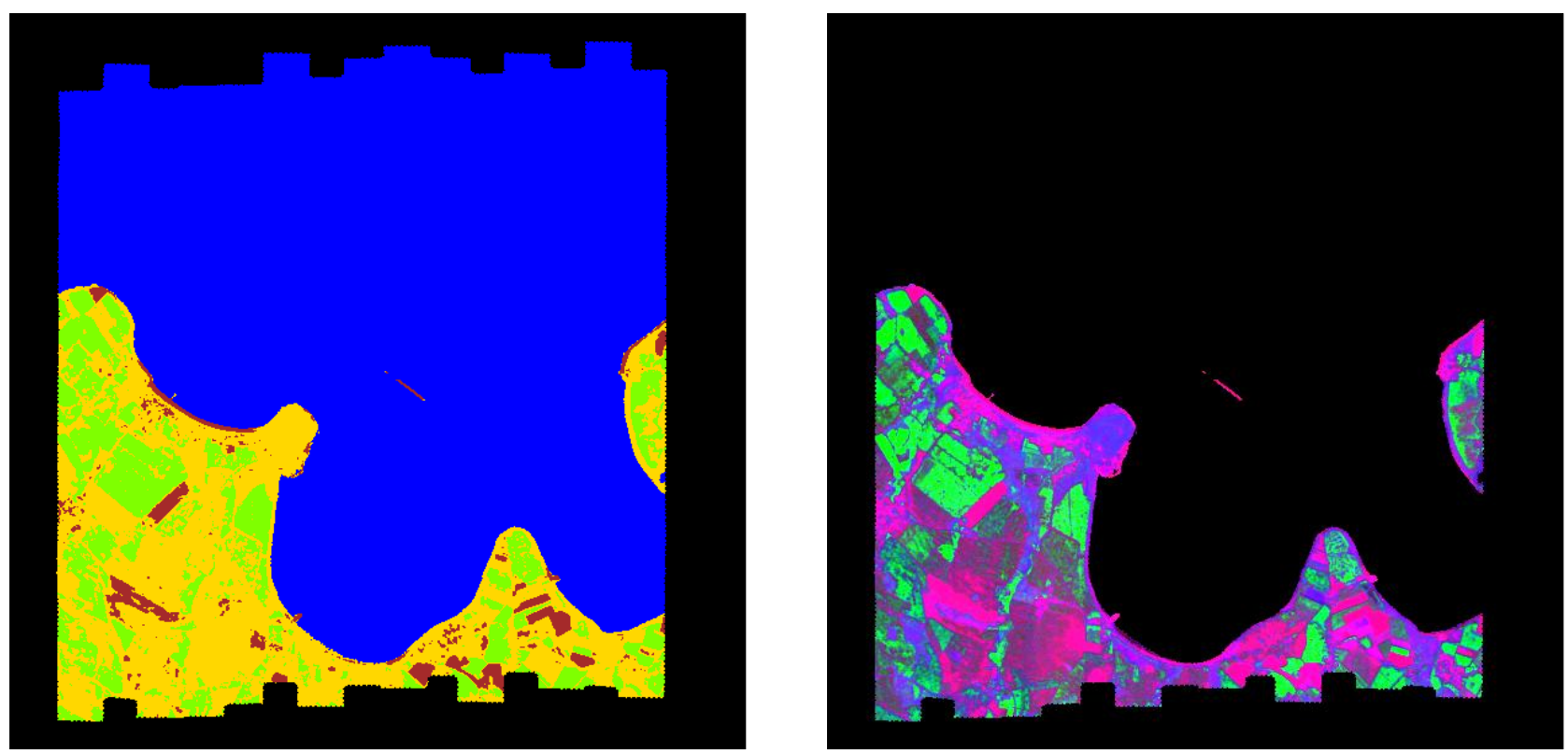

Figure 6: Left: Thematic land-use-classes colored (black = no data; blue = water; brown = soil / impervious surfaces; green $=$ photosynthetic active vegetation; yellow $=$ photosynthetic inactive vegetation)

Right: Land-use-classes colored as RGB image (Red = soil / impervious surfaces; Green = photosynthetic active vegetation; Blue $=$ photosynthetic inactive vegetation $)$. Mixed classes appear as mixed colors (i.e. soil + photosynthetic inactive vegetation $=$ red + blue $=$ magenta) .
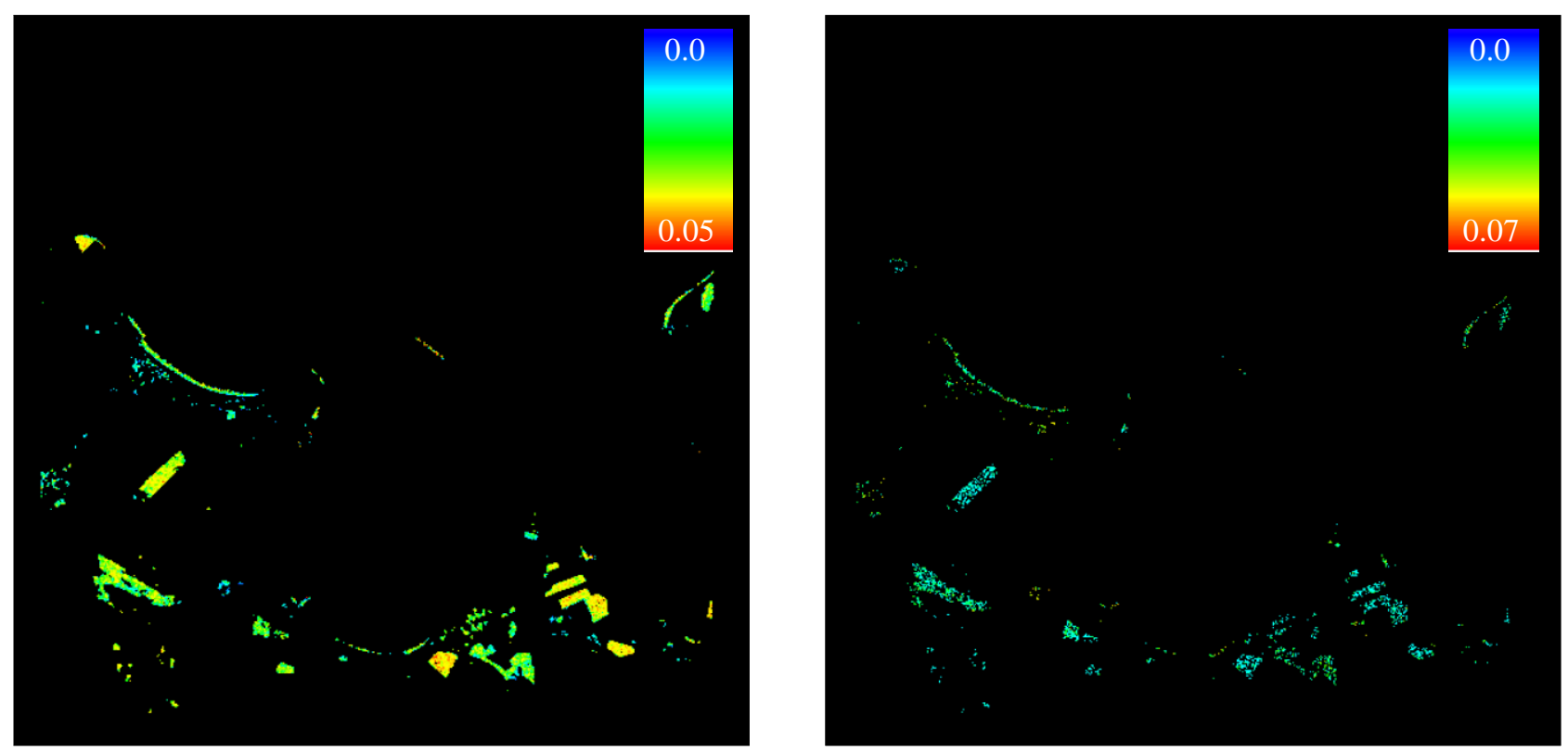

Figure 7: Left: relative clay content (color space: blue $=0.0$; red $=0.05$; units are relative absorption strength) Right: relative carbonate content (color space: blue $=0.0$; red $=0.07$; units are relative absorption strength)

As a next step, land-use-classes are calculated to get more detailed information about land surfaces. By calculating three different kind of coefficients, every pixel is labeled as one of the thematic classes "photosynthetically active vegetation", "photosynthetically inactive vegetation" or "soil and impervious surfaces". Water pixel were already defined by the 
calculation of a water mask. If mixed pixels appear, the highest fractional abundance decides the assignment to a thematic class (Figure $6 \mathrm{left}$ ). This strict classification leads sometimes to results slightly differing from the reality. Nevertheless, every class is presentable as a greyscale image (simply showing the abundance of a specific class) or as a colored (RGB) image (Figure 6 right).

The last step of the land module is the quantification of relative mineral contents. The best way to map the results is to color the values in a predefined color space. In Figure 7, a color space over the whole spectrum from blue to red is chosen, which represents values in the range $0-0.05$ for relative clay content (Figure 7 left) and $0.0-0.07$ for carbonate (Figure 7 right). The units for the soil mineral contents are relative absorption strength, which can be calibrated to derive quantitative material contents [see e.g., 22]. Mineral contents are calculated only for pixels classified as soil or impervious surfaces.

\section{Bathymetric Charts}

The results shown in Figure 8 are based on an original HySpex scene, which image section represents a suitable coastal area with shoals and water depths up to $6 \mathrm{~m}$. To perform the bathymetric tool with simulated EnMAP data, some adaptions of the algorithm will be implemented soon.
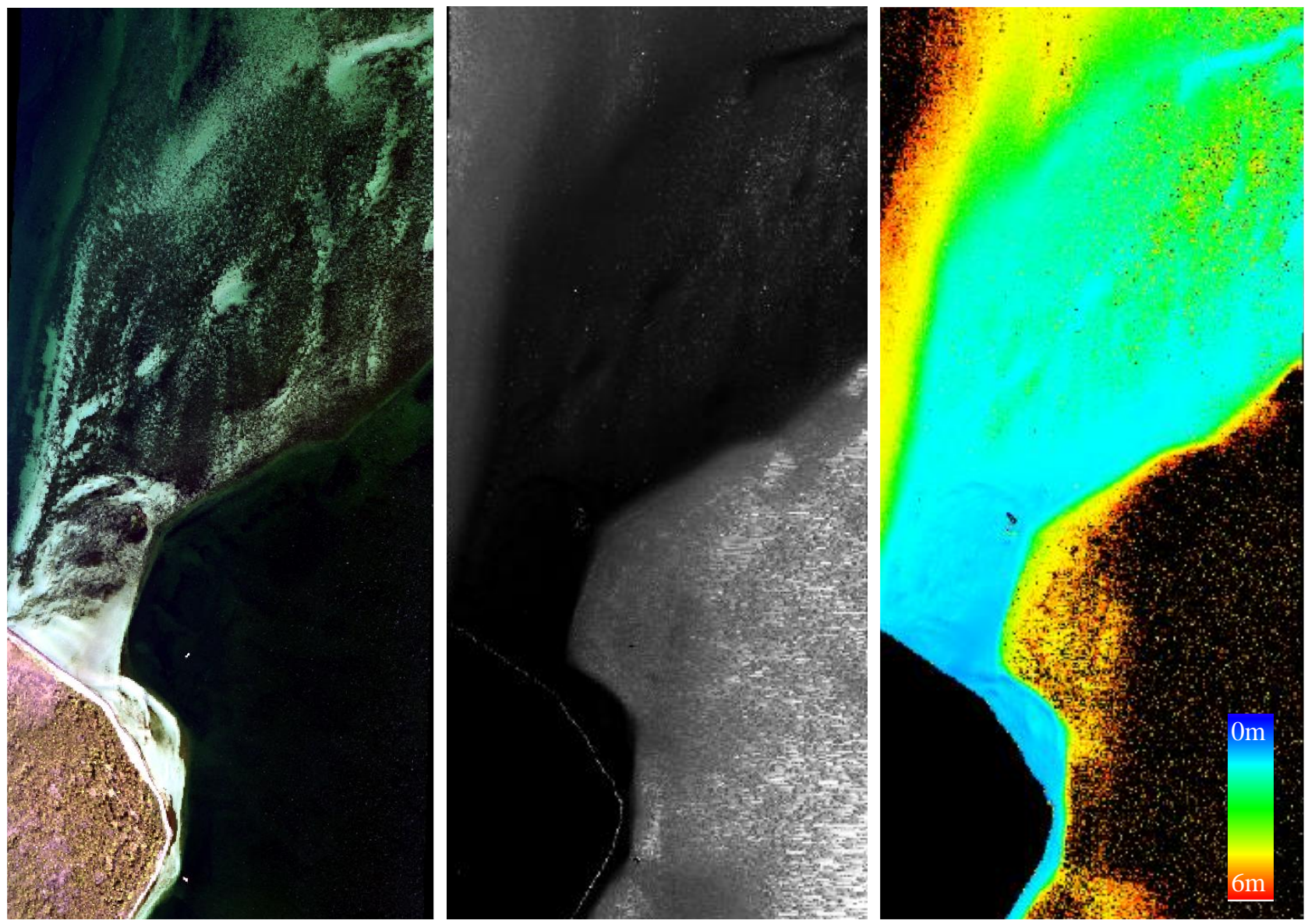

Figure 8: Left: false color band combination. Middle: water depth (greyscale image). Right: water depth (color space: blue $=0 \mathrm{~m}$; red $=6 \mathrm{~m})$ 
While the greyscale image prevents the detailed distinction between single values of water depths (Figure 8 middle), a color mapping represents clearly the different water depths (Figure 8 right). The false color image represents water depths only up to $6 \mathrm{~m}$. Therefore, a black pixel does not mean "no data", but water depths deeper than $6 \mathrm{~m}$. Still, some isolated pixels in these areas are classified as water depths between $4-6 \mathrm{~m}$, most likely for the influence of noise and wrong classification. Nevertheless, comparing the results visually with nautical bathymetric maps, they seem to be trustable and represent meaningful depths.

\section{CONCLUSION AND OUTLOOK}

To support the planning and execution of marine (landing) operations, a GIS plug-in tool was implemented to analyze hyperspectral remote sensing data with respect to land and water surfaces. Due to the lack of spaceborne hyperspectral data, recorded airborne data were used to simulate future EnMAP data. After applying the described modules first to original HySpex data, all results were satisfying and mostly free of noise. Using simulated EnMAP data (except for the bathymetric tool, for which some adaption have to be implemented still) lead to comparable satisfying results shown in this work. A validation work is in progress to achieve detailed quality indexes. If the results of the detailed validation should confirm the meaningful visual inspection, the potential of future EnMAP data for naval operations could be assessed more reliably. Indeed, as the simulated data are only able to predict future EnMAP data as good as possible, adaptions and design corrections when first EnMAP data are available will be necessary.

Still, after having positive feedback of the principal and the end users, future work and extensions are anticipated. The field of application will be extended by integrating the whole system design to the ESRI GIS platform for further analysts. Another possible extension could be the additional implementation of analyzing tools based on the data performed with this plug-in. Helpful would be other data sources like elevation, meteorological data and mission planning details, which lead to an additional information gain.

The system development was realized in close interaction with the principal and the end users, to secure the deployment is congruent with their expectations. This is why finally, as a very last step of a system design, the introduction and training of the end user will be important to guaranty the usability and value of the tool.

\section{ACKNOWLEDGEMENTS}

The authors would like to thank Dr. Karl Segl from GFZ for the EeteS EnMAP simulations based on the HySpex data. 


\section{REFERENCES}

[1] Berni, J. A. J.; Zarco-Tejada, P. J.; Suárez Barranco, M. D.; Fereres Castiel, E.; Thermal and Narrow-band Multispectral Remote Sensing for Vegetation Monitoring from an Unmanned Aerial Vehicle. IEEE Transactions on Geoscience and Remote Sensing 47(3): 722-738 (2009); doi: 10.1109/TGRS.2008.2010457

[2] Bürsing, H. \& Gross, W. (2017). Hyperspectral imaging: future applications in security systems. Advanced Optical Technologies, 6(2), pp. 61-66. Retrieved 5 Apr. 2017, from doi:10.1515/aot-2017-0007

[3] Clark, R. N. (1999). Spectroscopy of rocks and minerals, and principles of spectroscopy. Manual of remote sensing, 3 (3-58), $2-2$.

[4] Colomina I., Molina P.; Unmanned aerial systems for photogrammetry and remote sensing: A review. ISPRS Journal of Photogrammetry and Remote Sensing, Volume 92, June 2014, Pages 79-97

[5] Daughtry, C. S. (2001). Discriminating crop residues from soil by shortwave infrared reflectance. Agronomy Journal, 93(1), 125-131.

[6] Segl, K.; Rogass, C.; Kuester, T.; Roessner, S.; Kaufmann, H.; Sang, B.; Mogulsky, V.; Hofer, S. (2012). EeteS The EnMAP End-to-End- Simulation Tool. IEEE J. Selected Topics in Applied Earth Observation and Remote Sensing, Vol. 5, No. 2.

[7] Gege, P. (2014). WASI-2D: A software tool for regionally optimized analysis of imaging spectrometer data from deep and shallow waters. Computers \& Geosciences, 62, 208-215.

[8] Gross W.; Boehler J.; Schilling H.; Middelmann W.; Weyermann J.; Wellig P.; Oechslin R.; Kneubuehler M.; Assessment of target detection limits in hyperspectral data. Proc. SPIE 9653, Target and Background Signatures, 96530J (October 21, 2015); doi:10.1117/12.2192197.

[9] Guanter, L.; Kaufmann, H.; Segl, K.; Foerster, S.; Rogass, C.; Chabrillat, S.; et al. (2015). The EnMAP spaceborne imaging spectroscopy mission for earth observation. Remote Sensing, 7(7), 8830-8857.

[10] Haraké, L.; Schilling, H.; Blohm, C.; Hillemann, M.; Lenz, A.; Becker, M.; Keskin, G.; Middelmann, W.; Concept for an Airborne Real-Time ISR System with Multi-Sensor 3D Data Acquisition. Proc. SPIE 9987, Electro-Optical and Infrared Systems: Technology and Applications XIII, 998709 (21 October 2016); doi: 10.1117/12.2241051.

[11] Keskin, G., Schilling, H.; Lenz, A.; Groß, W.; Middelmann, W.; Ship classification in terrestrial hyperspectral data. Proc. SPIE 10004, Image and Signal Processing for Remote Sensing XXII, 100040U (October 25, 2016); doi:10.1117/12.2240875.

[12] Maerker, J.; Groß, W.; Middelmann, W.; Ebert, A.; Hyperspectral band selection using statistical models. Proc. SPIE 8048, Algorithms and Technologies for Multispectral, Hyperspectral, and Ultraspectral Imagery XVII, 80481Q (May 20, 2011); doi:10.1117/12.884098.

[13] Perpeet, D.; Gross, W.; Middelmann, W.; Automatic generation of digital terrain models from LiDAR and hyperspectral data using Bayesian networks. Proc. SPIE 8537, Image and Signal Processing for Remote Sensing XVIII, 85370W (November 8, 2012); doi:10.1117/12.974614.

[14]Richter, R. \& Schläpfer, D.; Atmospheric / Topographic Correction for Satellite Imagery. Report DLR-IB 56501/09. 2009.

[15] Rodger, A.; Laukamp, C.; Haest, M. \& Cudahy, T. (2012). A simple quadratic method of absorption feature wavelength estimation in continuum removed spectra. Remote sensing of environment, 118, 273-283.

[16] Schilling, H.; Bulatov, D.; Middelmann, W. (2015): Object-based detection of vehicles in airborne data. In: Proc. SPIE 9643, Image and Signal Processing for Remote Sensing XXI, 964316 (October 15, 2015); doi:10.1117/12.2194764.

[17] Schilling, H.; Lenz, A.; Gross, W.; Perpeet, D.; Wuttke, S.; Middelmann, W. (2013): Concept and integration of an on-line quasi-operational airborne hyperspectral remote sensing system, Proc. SPIE 8897, Electro-Optical Remote Sensing, Photonic Technologies, and Applications VII; and Military Applications in Hyperspectral Imaging and High Spatial Resolution Sensing, 88970V.

[18] Schilling, H.; Gross, W.; Middelmann, W.; Self-adaptive road tracking in hyperspectral data for C-IED. Proc. SPIE 8515, Imaging Spectrometry XVII, 85150S (October 15, 2012); doi:10.1117/12.929695.

[19] Smith, R. C. \& Baker, K. S. (1981). Optical properties of the clearest natural waters (200-800 nm). Applied optics, 20(2), 177-184.

[20] Tucker, C. J. (1979). Red and photographic infrared linear combinations for monitoring vegetation. Remote sensing of Environment, 8(2), 127-150.

[21] Yokoya, N.; Yairi, T.; and Iwasaki, A. (2012). Coupled nonnegative matrix factorization unmixing for hyperspectral and multispectral data fusion. IEEE Transactions on Geoscience and Remote Sensing, 50(2), 528-537. 
[22] Bayer, A.; Bachmann, M.; Rogge, D.; Müller, A.; Kaufmann, H. (2016) Combining Field and Imaging Spectroscopy to Map Soil Organic Carbon in a Semiarid Environment. IEEE Journal of Selected Topics in Applied Earth Observations and Remote Sensing, 9 (9). 